\title{
La Historia del libro en los manuales escolares argentinos. El caso de la historia medieval. ${ }^{1}$
}

por David Waiman

dwaiman@hotmail.com

Universidad Nacional del Sur

Recibido: 04/05/2019 - Aceptado: 03/06/2019

\section{Resumen}

La historia del libro es marginal en el entramado textual de la manualística y, generalmente, aparece entrelazada en pocas líneas narrativas, en un armazón general de otros temas que los engloban y que pertenecen a esferas políticas y socio - económicas más que culturales. A pesar de la ubicación periférica en la espacialidad discursiva de los manuales escolares, detectamos al libro como objeto de análisis en sí mismo. Solo hay dos editoriales que lo incorporan como tema de estudio, Puerto de Palos y Estrada, ambas de origen nacional. Esto explica en gran parte la libertad mínima pero existente que poseen estas editoriales en detrimento de las internacionales que planifican contenidos para mercados más amplios.

\section{Palabras claves}

historia cultural, manuales escolares argentinos, libros medievales

\section{The History of the book in the Argentine school textbooks. The case of medieval history.}

\section{Abstract}

The history of the book is marginal in the textual framework of the textbook and generally appears intertwined in a few narrative lines of other themes that encompass them and that belong to political and socio- economic rather than cultural spheres. Despite the peripheral location in the discursive spatiality of school textbooks, we detect the book as an object of analysis in itself. There are only two publishing houses that incorporate it as a subject of study, Puerto de Palos and Estrada, both of national origin. This largely explains the minimal but existing freedom that these publishers have, to the detriment of international ones that plan content for broader markets.

Keywords

cultural history, argentine school textbooks, medieval books 


\section{Los manuales escolares como fuentes históricas y la historia cultural.}

Los manuales escolares entendidos como fuentes históricas, esto es, representaciones ideológicas $^{2}$ de un tiempo y espacio concreto, son el soporte para llevar a cabo esta investigación. En lo temporal nos ubicamos dentro de un arco que va desde 1995 cuando se crean los Contenidos Básicos Comunes producto de la Ley Federal de Educación hasta 2006 cuando la Ley de Educación Nacional reemplaza a la normativa anterior. En lo espacial, analizamos la Argentina en su conjunto ya que los manuales confeccionados en Ciudad de Buenos Aires, tienen alcance nacional, a pesar de que muchas provincias rechazan esta reforma educativa.

Dichas herramientas didácticas son regladas, en primera instancia, por el Estado, a través de los diseños curriculares, y pensadas - producidas por editoriales que reparten las labores en dos actores de importancia dispar, los autores (desdibujados en su visibilidad individualizada y selección de contenidos) y los editores (cuyo peso es definitorio en las maquetaciones y el diseño como también en el tratamiento de los contenidos educativos). En esta lógica particular, y sin introducirnos en el uso del manual dentro del aula, es que nos preguntamos cómo analizan los autores - editores los contenidos medievales dentro de la discursiva manualística del período abordado y que dinámica historiográfica opera en ese material didáctico.

Dentro de la historiografía escolar ${ }^{3}$ que se analiza en los manuales, observamos unos discursos jerarquizados en lo que concierne a Historia Medieval. Primero, se visibilizan aquellos elementos basados en relatos de corte político - institucional, cuyas historias realzan las imágenes de reyes y monarquías, de imperios y papados, recuperando explicaciones más apropiadas del siglo XIX que del XXI. En segundo lugar, aparecen las temáticas socio-económicas (el campesinado y las ciudades), analizadas bajo la influencia de la historiografía francesa de Annales, especialmente, bajo la preeminencia de la primera y segunda generación, lo que también demuestra un arcaísmo historiográfico ${ }^{4}$ para finales de la década del noventa ${ }^{5}$. Por último, aparecen los temas culturales (temas que no tienen importancia cuantitativa en los diseños curriculares y tampoco en el armado historiográfico de los manuales). Es ahí donde situamos el desarrollo del libro como objeto de estudio en la manualística estudiada.

Esa historiografía cultural que parece tener mucha vitalidad en los espacios académicos universitarios actuales no se corresponde con el armado de los manuales escolares de educación media, lo que nos hace poner en duda la transposición didáctica y repensar nuevas nociones en torno a las categorías cultura escolar (Julia, 2001) y disciplinas escolares (Chervel, 1991) como resistencias a los cambios, con lógica y dinamismo propio, diferente a otros espacios del saber. Para reflexionar sobre estas problemáticas, analizamos los elementos culturales, como destacados marginales y periféricos de los relatos educativos en los manuales que los integran dentro de sus discursos históricos, centrándonos especialmente en aquellos vinculados al libro medieval y a la cultura escrita ${ }^{6}$.

En ¿Qué es la historia cultural?, Burke (2006) identifica una evolución de la misma dentro de la historiografía que nos sitúa en límites tan flexibles como son los campos de lo popular, el saber y los libros, la memoria, el arte o las percepciones y emociones de los individuos. Esa historia cultural y, en especial la centrada en los libros, se presenta, al decir de Bajtin (1998), bajo una polifonía aludiendo a las diferentes voces que pueden oírse en un único texto. Consideramos, sin embargo, que hay diferentes tonos de voces empleados, altos (político-militares) y bajos (socio-económicos), voces susurrantes que transcurren apenas perceptibles (estudios culturales), incluso voces que son silenciadas en las generalidades del texto (Historia de las mujeres, de la niñez o de los sectores populares).

En definitiva, a pesar de observarse una revolución historiográfica en el mundo académico, no ocurre lo mismo con la cultura escolar y el desarrollo historiográfico de las disciplinas escolares, en especial de la Historia ${ }^{7}$. Los temas novedosos, como los culturales, son marginales en el entramado textual de la manualística y, generalmente, aparecen entrelazados en pocas líneas narrativas, en un armazón general de otros temas que los engloban y que pertenecen a esferas institucionales más que culturales. 
A pesar de la ubicación periférica en la espacialidad discursiva detectamos en el libro, como objeto de análisis en sí mismo, que posee relativamente un valor autónomo en el tratamiento escolar de las pocas editoriales que se animan a presentarlo como tema de estudio. Se asocia con la memoria y la importancia de recordar ${ }^{8}$ que detentan determinados sectores socio - económicos a lo largo de la historia medieval, monopolizadores del saber, poniendo centralidad al libro como espacio de lo escriturario, más que con la lectura.

\section{Los libros medievales como objetos de estudio de la manualística escolar.}

Solo hay dos editoriales que incorporan al libro medieval como objeto de estudio en sí mismo, ambas de carácter nacional ${ }^{9}$. Puerto de Palos, representando una editorial relativamente joven e innovadora en el mercado y Estrada cuyo origen se remonta a 1869, dando un enfoque generalmente más tradicional a los temas históricos abordados. Analizar el libro dentro del libro nos presenta una realidad coherente en estos manuales analizados. En ambos casos, se mantiene una lógica organizativa en todo el recorrido de las ediciones, ya que ambas sostienen un relato que inicia con la importancia de la escritura para la Historia ${ }^{10}$, diferenciando la Prehistoria por ausencia de soportes escriturarios ${ }^{11}$.

Si nos centramos en lo cuantitativo, observamos que Puerto de Palos dedica al tratamiento de los libros una carilla y, aunque la espacialidad es pobre si se compara con otros temas políticos o económicos, se inserta en un conjunto temático mayor titulado "La cultura en la Edad Media" donde se analizan la educación, las universidades y la enseñanza dentro de las mismas y, finalmente, los libros, ocupando el conjunto tres carillas totales en una narrativa que pone foco en la historia de la educación durante el medioevo. Con respecto a Estrada, la espacialidad otorgada es de dos carillas para el estudio de los manuscritos y, a diferencia de Puerto de Palos, se inserta dentro de lo que denominan "Arte medieval" dejando una vinculación directa, aunque no subordinada, con la historia del arte ${ }^{12}$ y, especialmente con lo románico como valor asociativo de los manuscritos. En suma, mientras la primera editorial visibiliza la categoría cultural como voz sonante en sus discursos, la segunda la inserta dentro de la historia del arte, no pronunciando el vocablo cultura o cultural entre las palabras que utiliza en su narrativa.

En el caso de Puerto de Palos, observamos una incongruencia entre el uso del término cultura utilizado en la parte general, de manera reiterada ${ }^{13}$ y, en la específica (dedicada a los libros) donde el mencionado vocablo no se visibiliza en absoluto. Para esta editorial, el concepto se define citando autores de los años sesenta-setenta vinculados al mundo anglosajón:

A lo largo de doscientos años (siglos XII y XIII), la Edad Media contribuyó a la cultura con grandes aportaciones que subsisten todavía. Se fundaron las universidades, surgieron las primicias de la literatura occidental moderna; una filosofía de la ética reafirmó la Revelación en el terreno religioso; los gustos estéticos se articularon en la arquitectura de las catedrales, en los frescos y en la música polifónica. ${ }^{14}$ (Fremantle, 1979:s/d)

Téngase en cuenta que la utilización del término cultura, del que se apropia Puerto de Palos, define ampliamente el término, aunque poniendo su centralidad en elementos, vinculados a una cultura occidental caracterizada por valores cristianos. En el caso de Estrada registramos la ausencia completa del término cultura dentro del entramado discursivo referente a las artes medievales, no reconociendo directamente al libro como referencia de estudios historiográficos culturales.

Con respecto al estudio del libro en sí mismo, mientras Puerto de Palos sostiene la importancia del libro, de manera simétrica, con la categoría manuscritos, lo que nos indica su conexión fuerte con el mundo de los copistas y el hacer de los textos; Estrada, por su parte, prioriza el término libro por sobre manuscritos, englobando en la decisión una postura más general, al tiempo que compleja, del concepto a trabajarse, lo que se manifiesta a través de los diferentes tipos de soportes que Estrada menciona y sus formatos escriturarios más amplios a lo largo de todo el relato. 
Gráfico $\mathbf{N}^{\mathbf{0}}$ 1. Elaboración propia.

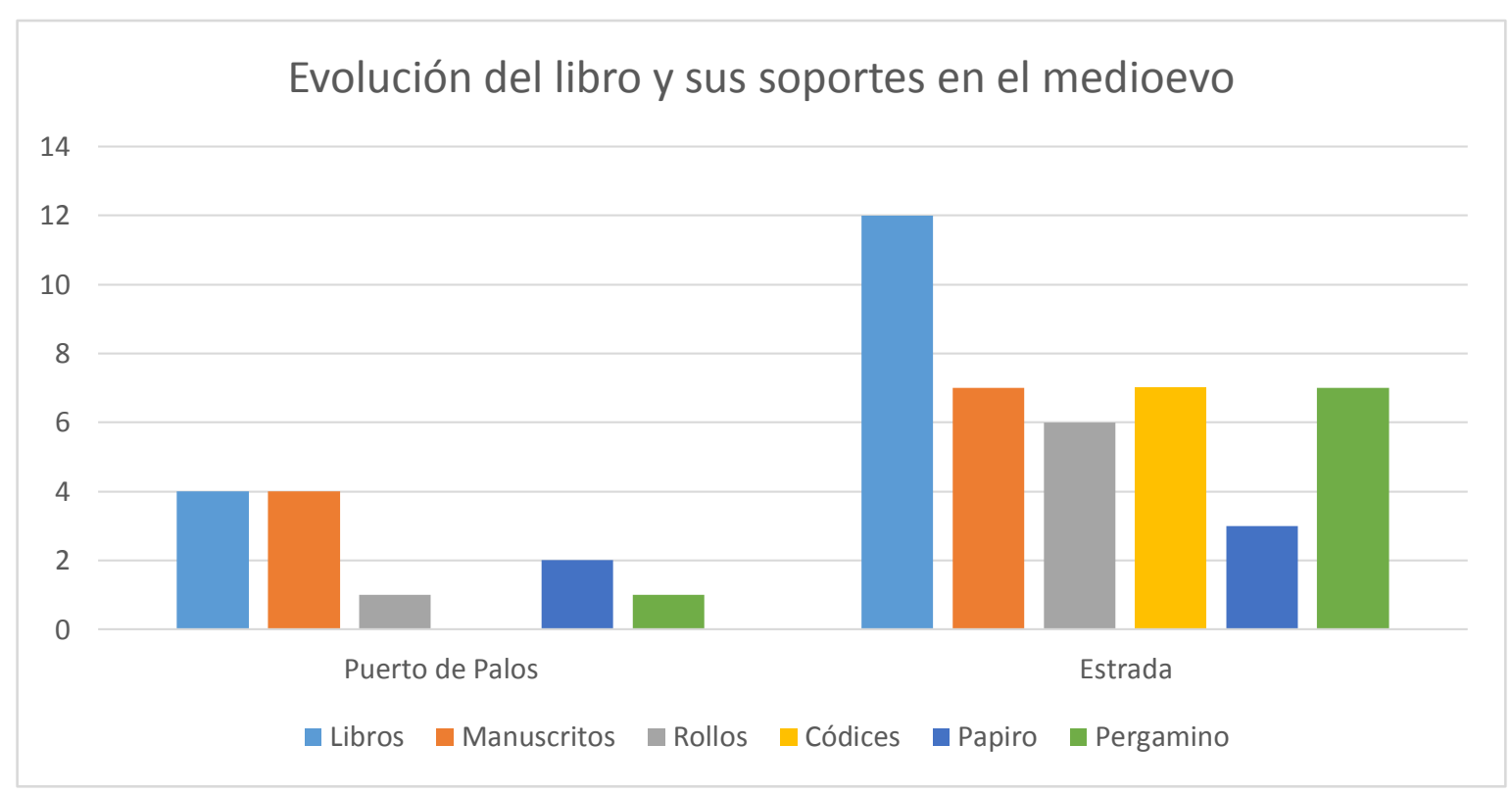

Como observamos en el gráfico $\mathrm{N}^{\mathrm{o}} 1$, Puerto de Palos plantea de forma marginal el tema de los formatos escriturarios, dejando fuera de la narrativa a los códices, elementos esenciales de la cultura medieval $^{15}$, a los que se confunde con los pergaminos, esto es, con los soportes en los que se vuelcan los contenidos. Es así que se expresa:

Los textos, habitualmente los evangelios o libros de salmos, se realizaban en papiro, material muy caro, frágil y que se podía escribir en una sola cara; los rollos de papiro se denominaban volumen. Más adelante, al generalizarse el uso del pergamino... las hojas dobladas y cosidas, fueron apiladas y sujetadas por el borde. (AA. VV., 2001:190) ${ }^{16}$

La conformación explicativa lleva a indefiniciones que pueden derivar en formas de reproducción memorística del público al que se destine la información, pues la narrativa carece de precisiones cronológicas ("más adelante") como también conceptuales (no se precisa que es el papiro o el pergamino de forma concreta).

Con respecto a Estrada, se analiza la evolución del libro desde su formato antiguo hasta el alcanzado en los tiempos medievales, al decirse que:

Los primeros libros de Occidente no tenían la forma de los actuales: eran rollos de papiro escritos de un solo lado y, para leerlos, había que sujetarlos con las dos manos...los libros se debían copiar uno por uno: eran manuscritos, es decir, escritos a mano...Con la aparición del cristianismo, se fue imponiendo, poco a poco, una nueva forma para los libros: el códice, que es la que tienen los libros actuales. (AA. VV., 2003:258)

Si bien Estrada, al igual que Puerto de Palos, plantea una historia del libro basada en lo occidental cristiano con evidentes imprecisiones cronológicas, se diferencia en la claridad a la hora de dar definiciones, precisándole al lector, dentro del propio discurso los significados como el de manuscrito, a la vez que, representando, de forma sencilla, una evolución didáctica de los diferentes formatos a lo largo del tiempo, tomando como referencia constante el libro actual al que los lectores observan como modelo comparativo.

Estrada, a diferencia de la otra editorial, no solo aborda ampliamente el tema de los códices y su soporte, el pergamino; sino que los define con vivencia clara. Sobre los primeros, se expresa que son: 
... un conjunto de páginas unidas por uno de sus lados (el lomo). Los códices de esa época eran, en su mayoría, de pergamino, es decir, de un cuero muy fino y pulido. Resultaban más baratos que los rollos, por dos razones: porque a diferencia del papiro -importado de Egipto- el pergamino podía conseguirse en cualquier lugar, y porque los códices permitían que se escribiera de los dos lados de la hoja. (Idem)

Consideramos que ambas editoriales insertan al libro dentro de los marcos generales de estudios culturales; sin embargo, el nivel de tratamiento, respecto del libro y su contexto de producción, alcanza un alto desarrollo en la editorial Estrada, lo que facilitaría, en caso de trabajarse en el aula, el acercamiento comprensivo del tema al joven lector o, incluso, a docentes que adquieren el material por primera vez y no son especialistas en lo medieval, facilitando los procesos de transmisión del conocimiento específico de manera más clara.

Por último, nos interesa analizar la importancia que posee la escritura en relación a los copistas, como también, frente a las ilustraciones que acompañan las narrativas textuales y su vinculación con el rol otorgado a la lectura.

En el caso de Puerto de Palos (gráfico $\mathrm{N}^{\mathrm{o}}$ 2), observamos que los términos que se imponen son los referidos a la escritura, en concordancia con un discurso que valoriza la cultura escrita como central en la narrativa. En segundo lugar, aparece la imagen y su producción a la que se dedica un apartado denominado "Las iluminaciones". En tercer lugar, el texto visibiliza a los copistas, poniendo materialidad representativa en esos monjes que vuelcan, a través del Scriptorium, su arte, el de conservar los textos pasados, en tanto salvaguarda de una memoria colectiva o, al menos, la de un grupo con poder. Por último, se encuentra, desde una posición marginal, la lectura, esto es, aquella faceta del libro que emana sonoridad y voz representando en la cultura medieval el acercamiento del texto escrito hacia una mayoría de hombres y mujeres analfabetos.

\section{Gráfico $\mathbf{N}^{\mathbf{0}} 2$. Elaboración propia.}

Puerto de Palos

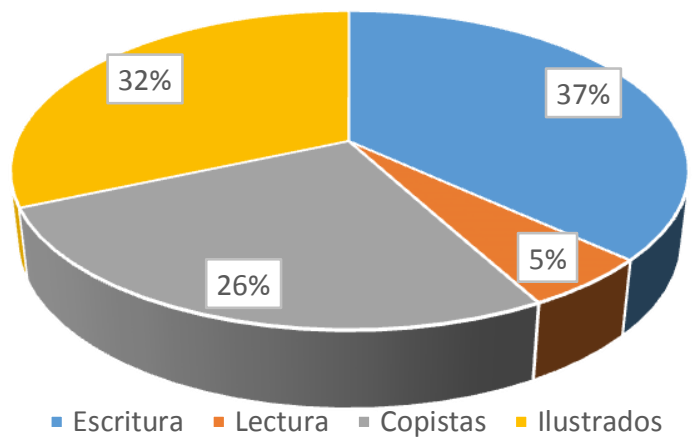

Estrada

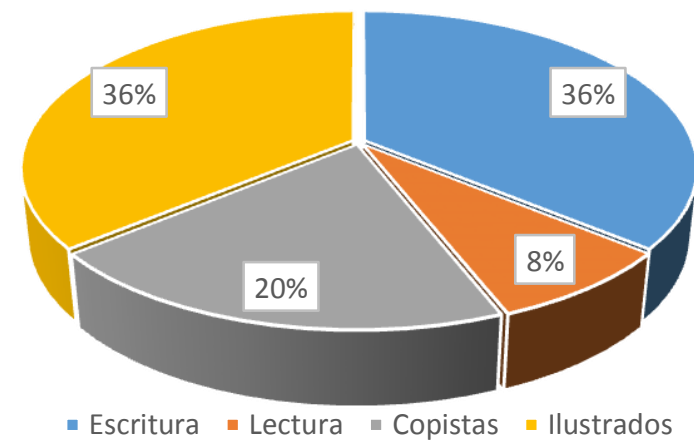

Si comparamos el gráfico $\mathrm{N}^{\circ} 2$, notamos una primera y gran diferencia entre la editorial Puerto de Palos y Estrada. Para esta última, se pone en pie de igualdad ${ }^{17}$ imagen y palabra, esto es, los símbolos referentes a lo iconográfico y lo narrativo, lo que tiene su lógica al expresarse que dicho tema forma parte de la historia del arte, a pesar de titularse "Los manuscritos medievales", haciendo pensar, a simple vista, que solo dedica esfuerzos a explicar la cultura escrita. En segundo lugar, se coloca la relación con los copistas, más baja en representación que la que adquiere para Puerto de Palos. En tercer lugar, ubicamos a la lectura, manteniendo una posición periférica con respecto a los otros elementos existentes. 
Con respecto al binomio escritura - ilustraciones, Puerto de Palos lo ubica fuera del texto principal, en un recuadro periférico, en lo que denominan "Las iluminaciones", donde se ponen en diálogo con las miniaturas, al expresarse que:

La composición de una página iluminada pasaba por una serie de etapas: en primer lugar el trazado a lápiz de todos los elementos de la composición...luego la aplicación de las tintas, y finalmente las labores de dorado y realzado. El color rojo, ampliamente utilizado, se obtenía mezclando minio con clara o yema de huevo...El término miniatura que se aplica a las ilustraciones realizadas según este procedimiento, alude al uso que del minio se hacía para su confección. (AA. VV., 2001:190)

A pesar de plantear los pasos pertinentes a la confección de iluminaciones en un formato que entendemos claro para el lector, no termina definiendo ninguno de los conceptos claves que plantea, con el agravante de conectar confusamente las iluminaciones y las miniaturas. Destacamos, sin embargo, una imagen icónica que acompaña al desarrollo del discurso, que aunque no posee referencia alguna, muestra un folio de libro medieval en el que conviven infinitud de colores, dibujos pictóricos y, bajo los mismos, un texto, demostrando la coexistencia de escritura e imagen en la misma espacialidad (Imagen 1$)^{18}$.

Figura $\mathbf{N}^{\mathbf{0}}$ 1. Cuaderno de patrones góticos tardíos de Stephan Schriber, monje del suroeste de Alemania, 1494.

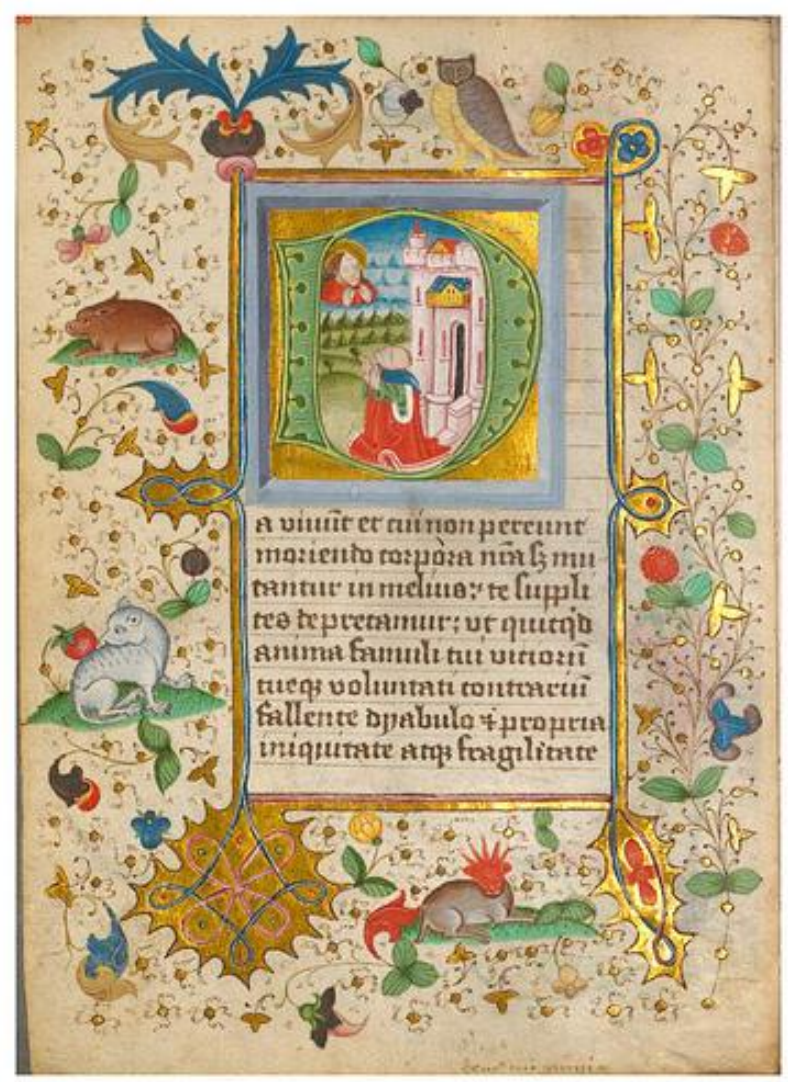

Estrada, una vez más, plantea una didáctica mayor ${ }^{19}$ al desarrollar categóricamente el tema desde sus definiciones claras y precisas, enunciando que:

Además de textos, los manuscritos medievales solían incluir distintos tipos de ilustraciones, que habitualmente eran realizadas por monjes especializados...Las letras iniciales de diferentes párrafos o capítulos también solían estar ilustradas... se ornamentaban con pequeñas ilustraciones autónomas. Eran conocidas como miniaturas, no por su tamaño, sino porque para 
pintarlas se utilizaba el minium -bermellón en latín-. Si además de colores se empleaba el oro...se las llamaba iluminaciones, de lumen - luz-. (AA. VV., 2003:259)

Estrada plantea las diferencias conceptuales entre aquellas miniaturas que son iluminadas y aquellas que no, en torno al valor del trabajo en oro que realizan especialistas ilustradores pertenecientes al mundo religioso medieval. Estas aportaciones son novedosas teniendo en cuenta la tradicionalidad discursiva que caracteriza a la editorial mencionada. Esta claridad narrativa ayuda a la comprensión de un tema nuevo como el del libro en la manualística pensando en el público juvenil que debe leer y trabajar este contenido, al que se complementa de letras carolinas ilustradas que refuerzan la relación texto - contexto. Es así que se presentan cuatro ejemplos ${ }^{20}$ iconográficos que acompañan la explicación específica. Dichas imágenes se ubican en posiciones importantes dentro de la carilla, compartiendo centralidad con el desarrollo de lo escrito.

En cuanto a los elementos escritura - copistas - lectura se puede realizar un análisis conjunto de las mencionadas categorías. Los dos primeros actúan como complementos ya que los escribas dan materialidad a la escritura, esto es, humanizan dicha práctica como motor de reproducción de la cultura. En ese escenario, la lectura aporta a la cultura escrita dinamismo y mayor marco de difusión, pensando en una sociedad eminentemente analfabeta, la cual depende de sujetos que tornen colectiva la acción de leer lo que previamente se escribe.

El copista adquiere para Puerto de Palos una doble funcionalidad referente al espacio donde actúe. Es así que:

Los manuscritos constituyeron una importante fuente de ingresos para los monasterios y abadías en los siglos IX y X. En el scriptorium, generalmente cerca de la biblioteca, los monjes copiaban y decoraban los manuscritos...A partir del siglo XII, antiguos colaboradores de los monjes en la tarea de iluminar manuscritos comenzaron a escribir los documentos oficiales de las ciudades; luego, organizaron talleres que ampliaron la producción mediante textos de filosofía, matemática y astronomía. La organización de talleres acortó los tiempos de realización de las copias y redujo los costos, de manera tal que los libros dejaron de ser objetos de lujo y se difundieron... en las universidades y en la burguesía. (AA. VV., 2001:190)

Coherente con el discurso mantenido en el abordaje del mundo urbano donde los artesanos y sus talleres adquieren real protagonismo, pone nuevamente al libro en una doble lectura de corte temporal. Por un lado, una alta Edad Media dominada por el accionar de monjes copistas cuyas obras se centran eminentemente en temáticas religiosas. Por otro lado, una baja Edad Media dominada por un nuevo tipo de copista urbano, el que no produce solamente para las esferas aristocráticas de la sociedad feudal, sino para un público más amplio, vinculado a esferas burguesas, el cual acompaña la entrada de nuevas temáticas al saber y la cultura de la época.

Si bien el mundo de la escritura y los copistas se muestra complejo y cambiante según los diferentes tiempos históricos; la lectura, evaluada como tercer factor de discusión, viene a poner en contradicción el discurso narrado previamente ya que, al principio del capítulo se inicia declarando que: "Durante la Edad Media, muy pocos laicos sabían leer y escribir", remarcada en negrita, cerrando el saber, de manera indirecta y homogénea a los hombres religiosos de la época y abriendo un interrogante: ¿Si los copistas producen cada vez más textos para nuevos públicos burgueses, como entender que haya pocos laicos letrados? Es en estos casos cuando observamos contradicciones historiográficas superpuestas dentro del discurso presentado por la editorial que no ayudarían a la comprensión histórica de los que abordan este tema.

En suma, se pone en entredicho la idea de una amplia producción de libros destinados a un nuevo público en la baja Edad Media y el pobre manejo de lectoescritura que poseen los laicos, mayormente vinculados con la burguesía en el relato, durante toda la Edad Media. Contradicción que vuelve al discurso frágil y confuso, corriendo el riesgo de estudiarse a través de formas memorísticas ${ }^{22}$ por su no comprensión general.

Con respecto a Estrada, la editorial centra al escriba dentro del mundo religioso. El copista coincide con la figura del monje, cerrando ese espacio a un contexto vinculado exclusivamente al 
poder cristiano de los primeros tiempos medievales, donde se analiza la escritura bajo un formato de fuerte conservación religiosa ${ }^{23}$, al decirse que: "Los monjes copiaban en los monasterios textos de carácter religioso... En algunos casos, también transcribían textos clásicos en latín y en griego, ya que necesitaban conocer $\mathrm{y}$, de alguna manera, practicar estas lenguas para leer los textos religiosos" (AA. VV., 2003:258).

La vinculación a los textos clásicos y profanos se da mediatizada por los lazos cristianos, dándose a entender; primero, que las lenguas que dominan la escritura de esos libros son las clásicas, eso es, latín o griego, dejando entrever rasgos culturales que conectan el pasado romano con la escritura analizada, reforzando la premisa que lo cultural se mueve en tiempos largos de duración; segundo, que la importancia de esos textos profanos es solo funcional a la sacralidad ejercida por la Iglesia. En ese sentido, tanto los copistas como la lectoescritura que ellos ejercen son operativos respecto de un bien superior, el de la institución eclesiástica y la conservación de su propio pasado.

Tanto en Puerto de Palos (Imagen $\mathrm{N}^{\mathrm{o}} 2$ ), como en Estrada (Imagen $\mathrm{N}^{\mathrm{o}} 3$ ), se acompaña el tema copistas con una imagen de un monje en su pupitre ejerciendo la tarea de escritura. En el caso de la primera se elige un icono de color sepia que abarca importantes dimensiones dentro del conjunto estudiado y visibiliza a Jean Miélot, representado como el letrado y copista ideal. Con respecto a la segunda, se plantea una obra de suaves colores, la que representa a Eadwine, monje benedictino del siglo XII, trabajando en la escritura de un manuscrito en el Scriptorium. Ambas imágenes vuelcan la idea de un trabajo solitario del monje donde la escritura es centro de la obra, careciendo de toda representación el acto de la lectura.

Figura $\mathbf{N}^{\circ} 2$

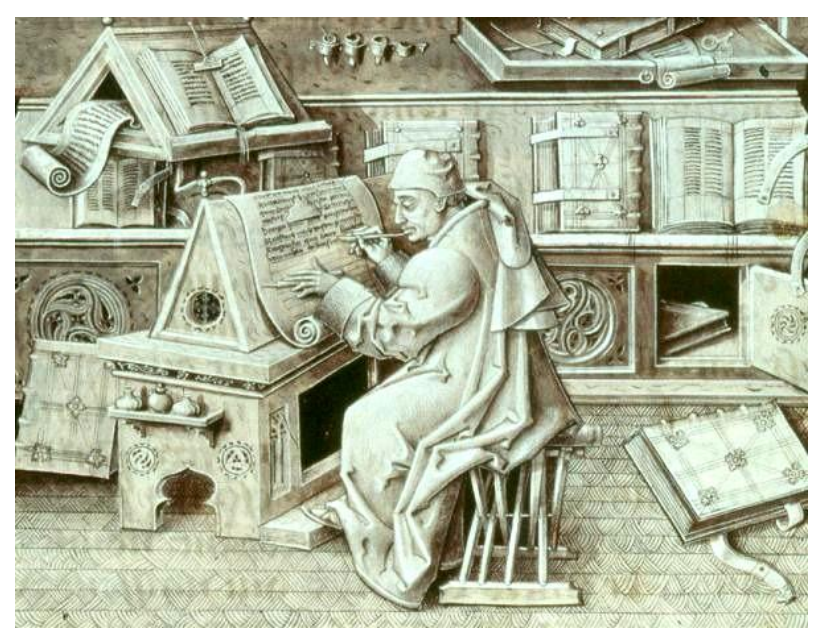

Figura $\mathbf{N}^{\mathbf{0}} 3$

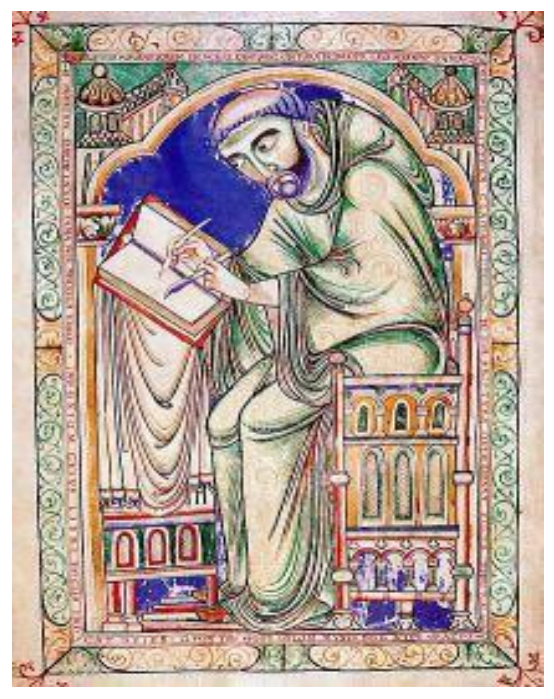

Estrada, con respecto a la lectura, sostiene dos ejes de análisis. Por un lado, se refuerza la unidad discursiva entre lectura, escritura y su materialización en la representación de los monjes - copistas, mediante su accionar como custodios de los libros sagrados y, por ende, de la religiosidad ${ }^{24}$ que de $^{2}$ ellos se desprende para toda la comunidad cristiana medieval. Por otro lado, plantea una lectura que une al texto con el copista en solitario y no como formato comunitario de distribución del saber.

El copista, durante la narrativa, se lo recorta en su dimensión de mero reproductor de libros, poniéndolo al nivel de una impresora humana y excluyendo del relato sus facetas más ricas y, tal vez, las que aportan mayores elementos a lo cultural como son el desarrollo y análisis de la escritura personal de los monjes con sus propios sellos literarios distintivos ${ }^{25}$ y también, los ejercicios de lectura individual y/o comunitaria que realizan dentro del monasterio para un público, con diversos problemas de analfabetismo. De estos elementos de la vida cotidiana en el monasterio ${ }^{26}$ nada se 
dice, transformándose en un discurso puramente técnico de los elementos escriturarios que necesita el monje para ejecutar la tarea de copia sobre manuscritos (tinteros, plumas, raspadores).

La idea de un monje copista va en concordancia con la idea central de este capítulo, demostrar que solo ellos pueden en este período histórico conservar la cultura en Occidente y reforzarla en cada reproducción recreada por medio de la escritura. Sobre esto, la misma editorial nos expresa: "Conocemos los libros elaborados en Irlanda, por ejemplo, gracias a los que se conservaron en los monasterios fundados por sus monjes en el resto de Europa, ya que durante las invasiones de los vikingos, estos destruyeron los monasterios de las islas y acabaron con casi todos sus libros" (AA. VV., 2003:258).

Consideramos a esta cita de suma claridad, ya que bucea en la profundidad del porqué se elige este tema, la importancia de indagarnos como sujetos históricos en los interrogantes del ¿Por qué RECORDAR? (Barret-Ducrocq, 2002). Y, en ello, ambas editoriales ponen un acento clave en la escritura como motor en la selección de una memoria, esto es, en un pasado que "implica la presencia de una cosa que está ausente" como dice Ricoeur (Ibídem:25), pero que logra revivirse cada vez que se vuelca en palabras, en textos o libros que se resignifican en cada proceso de gestación.

\section{Conclusión.}

En síntesis, este trabajo pretende reflexionar acerca de una historiografía escolar que no se condice con aquella abordada en los ámbitos especializados del saber académico. La mayoría de los manuales escolares, en especial, los de mayores tiradas en el mercado, refuerzan los relatos tradicionales del pasado medieval repitiendo, año tras año, idénticos esquemas explicativos donde los relatos culturales quedan fuera de cualquier tipo de análisis.

Traemos el tema de los libros en el marco de la cultura en la Edad Media, pues aparece al tiempo, como eje novedoso (rompe con los discursos políticos y económicos dominantes en la mayoría de los textos escolares) y marginal (solo es analizado en dos editoriales -Tinta Fresca y Estrada - como tema en sí mismo, o sea, con entidad propia).

Respecto a sus formatos explicativos, plantean varias críticas, las que aluden a la presentación del tema, claridad y coherencia argumentativa al proponer definiciones y contradicciones teóricas en la relación entre escritura y lectura. Sin embargo, incluso con las problemáticas marcadas hasta el momento, ambas editoriales destacan por romper el discurso historiográfico escolar tradicional y, arriesgarse, desde posiciones ideológicas diferentes, a unificar criterios frente a un tema novedoso, a nuestro entender, como es la historia del libro y sus diferentes representaciones, soportes y formatos. Esto visibiliza pequeños cambios que acercan, lentamente, ambas historiografías - la escolar y la académica- las cuales hoy se hallan disociadas casi por completo en detrimento de la enseñanza de los niveles medios.

\section{Bibliografía}

Bajtin, M. (1998). La cultura popular en la Edad Media y en el Renacimienta: e/ cantexta de Français Rabelais. Madrid: Alianza.

Barret-Ducrocq, F. (2002). ¿Par qué RECDRDAR? Barcelona: Granica.

Bowen, J. (1992). Historia de la Educación accidental. La civilización de Eurapa. Siglos VI - XVI, tomo II. Barcelona: Herder.

Burke, P. (2006). ¿¿Lué es la historia cultura/? Buenos Aires: Paidós.

Camille, M. (1992). Image an the Edge: The Margins af Medieval Art Cambridge: Harvard University Press.

Cardenal Montero, E. (2000). El Scriptorium altomedieval como vehícula transmisar de la cultura. En De la Iglesia Duarte, J. I. (coord.). La enseñanza en la Edad Media (403-412). Logroño: Institutos de Estudios Riojanos.

Chervel, André (1991). Historia de las disciplinas escolares. Reflexiones sobre un campo de investigación. Revista de Educación, 295, 59 - III. 
Cuesta Fernández, R. (1997). Saciagénesis de una disciplina escalar: la Historia. Barcelona: Pamares-Corredar. Fremantle, A. (1979). La Edad de la fe. Madrid: Time Life. Julia, D. (2001). La cultura escolar como objeto histórico. Revista Brasileira de História da Educaçãa, I, 9-44. Ricoeur, P. (2004). La memoria, la histaria y el alvida. Buenos Aires: FCE. Radríguez, M. \& Dabaño Fernández, P. (2001). Las libras de texta cama abjeta de estudia. Buenos Aires: La Colmena. Valls Montes, R. (20I2). Historiografía escolar española: siglos XIX - XXI. Madrid: UNED.

\section{Fuentes}

AA. V. (2001). Ciencias Saciales 7. Geagrafía- Historia - Formación ética y ciudadana. Buenos Aires: Puerto de Palos. AA. V. (2003). Ciencias Saciales 7. Buenos Aires: Estrada.

${ }^{1}$ Una versión preliminar fue presentada en la Mesa $N^{\circ} 123$ "La enseñanza de la historia. Perspectivas y enfoques teóricos y metodológicos", XVI Jornadas Interescuelas/ Departamentos de Historia, organizadas por la Universidad Nacional de Mar del Plata, los días 9 a 11 de agosto de 2017. Es parte de la tesis de Doctorado en Historia del autor (2018). La edad media en los manuales escolares bonaerenses: entre la textualidad y la iconicidad tradicionales (19992006). Bahía Blanca: UNS. Disponible en http://repositoriodigital.uns.edu.ar/

${ }^{2}$ Para mayor información sobre el tema Rodríguez y Dobaño (2001).

${ }^{3}$ Sobre esta categorización véase Valls Montes (2012).

${ }^{4}$ Esta categoría es presentada dentro del código disciplinar por Cuesta Fernández (1997).

5 Téngase presente que en el tema de las ciudades medievales se sigue retomando las ideas de Pirenne sobre su tratamiento, cuando en los ámbitos académicos, durante los años noventa, ya nadie sostiene dichas teorías, presentadas como "islas de plena libertad" en contraposición al feudalismo.

${ }^{6}$ De una muestra general de doce ejemplares de diversas editoriales nacionales e internacionales, el tema es abordado solamente por dos, lo que sitúa al mismo en clara posición de marginalidad.

${ }^{7}$ Se debe tener en cuenta que para la reforma educativa estudiada, lo medieval es abordado dentro de unas Ciencias Sociales que pretenden desdibujar los férreos límites entre dos disciplinas escolares tradicionales como son la Geografía y La Historia, no definiendo claramente, según mi opinión, las delimitaciones entre los campos del saber social, generando más incertidumbres que certezas en el campo de la acción.

${ }^{8}$ Véase Barret-Ducrocq (2002) y Ricoeur (2004).

${ }^{9}$ En 2006 el grupo trasnacional Macmillan compra Puerto de Palos y un año después hace lo propio con Estrada. Se consideran ambas nacionales hasta las fechas indicadas.

${ }^{10} \mathrm{Si}$ bien la mayoría de los manuales aceptan que la Historia comienza con la invención de la escritura y ponen fuerza discursiva en ello, luego dejan sin voz, al menos en el relato medieval, a los soportes y, por ende, a la misma escritura, notándose una contradicción real entre el inicio del relato y los discursos dedicados a un período histórico concreto.

${ }^{11}$ Esta versión tradicional de entender el abordaje histórico es común a la mayoría de los discursos en manuales de la época estudiada.

${ }^{12}$ Consideramos que, a pesar de tener fuerte relación con el mundo del arte (conectado intertextualmente con el discurso sobre románico), mantiene su peso discursivo autónomo dentro de la espacialidad otorgada por los editores.

${ }^{13}$ En los discursos generales sobre la educación y la enseñanza universitaria aparece cinco veces el vocablo cultura. Consideramos que ocupa una fuerte presencia discursiva si se compara con la parte específica, relativa a los libros, donde no aparece nunca dicho vocablo.

${ }^{14}$ Publicado originalmente en 1965 con lo que se considera un texto clásico entre las producciones culturales existentes. Esto nos da señales de la bibliografía que generalmente se usa por las editoriales y que raramente en coetánea a los manuales creados.

${ }^{15}$ Sobre este tema véase Cardenal Montero, 2000.

${ }^{16}$ Es así como la piel de cordero o ternero curtida y pulida se confunde en su descripción técnica con el códice que consiste en la unión de varios pergaminos que se unen, a través de una costura, en formato libro, perdiendo esa forma característica del pasado antiguo y de la temprana Edad Media dominada por los rollos de papiros.

${ }^{17} \mathrm{Si}$ bien Estrada sostiene los mismos porcentajes entre la escritura y las ilustraciones; Puerto de Palos pone a las imágenes en un lugar importante al ubicarla en un segundo puesto junto a las escrituras.

${ }^{18} \mathrm{La}$ imagen se encuentra sobre el párrafo periférico de las iluminaciones, en una posición y un tamaño aún más marginal que el texto escrito que referenciamos.

${ }_{19}$ Pensemos que el lector al que va dirigido el material tiene entre trece y catorce años, necesitando definiciones textuales acordes a su comprensión histórica.
} 


\footnotetext{
${ }^{20}$ Se visibilizan dos iniciales ornamentadas (la letra $\mathrm{C}$ y la $\mathrm{O}$ ), una letra $\mathrm{Q}$ historiada y lo más llamativo, a nuestro entender, es una página donde se visualizan en conjunto texto e ilustraciones como un todo dentro de un libro del siglo $\mathrm{XV}$.

${ }^{21}$ Idem. Sobre esta afirmación, controvertida y genérica, que alude a un clero homogéneamente letrado, especialmente si se piensa en los primeros siglos medievales, cf. Bowen, 1992.

${ }^{22}$ Estas prácticas nos recuerdan formatos tradicionales de enseñar historia, lo cual quitaría todo sesgo novedoso si no se comprende la importancia del porqué estudiar ese tema y cómo abordarlo.

${ }^{23}$ Se pone el foco en los intercambios de libros entre monasterios, proceso que es ayudado por el movimiento de peregrinaciones a Roma. No se cita nada referente a universidades o a los sectores burgueses urbanos como sí ocurre con Puerto de Palos.

${ }^{24}$ Usamos la palabra religiosidad y no cultura ya que la editorial no usa el segundo vocablo en su discurso.

${ }^{25}$ Sobre las anotaciones de los monjes copistas, podemos encontrar sentimientos, quejas o fantasías que no pueden expresarse a viva voz dentro del Scriptorium y que los monjes se encargan de dejar anotadas en los márgenes de los manuscritos que tienen a su cargo. Este tema lo trabaja Camille, 1992.

${ }^{26}$ Nada se dice de las religiosas mujeres, si pueden o no llevar a cabo la tarea de copistas como los hombres. Una vez más, se dirige el discurso hacia lo masculino.
} 